\title{
Pancytopenia related to azathioprine in rheumatoid arthritis
}

\author{
M E C JEURISSEN, A M Th BOERBOOMS, AND L B A VAN DE PUTTE \\ From the Department of Rheumatology, University Hospital Nijmegen. The Netherlands
}

SUMmaRY Two patients with rheumatoid arthritis developed pancytopenia during treatment with azathioprine $100 \mathrm{mg}$ daily. In one patient this side effect occurred after three weeks, in the other after eight weeks of treatment. Rapid fall of platelets in one patient necessitated platelet transfusion. In the other patient additional treatment with allopurinol was probably responsible for the toxic effect. Haematological side effects of azathioprine are discussed.

Key words: adverse drug reaction, bone marrow suppression.

Azathioprine has been extensively used for more than 20 years in the treatment of patients with rheumatoid arthritis (RA) who are unresponsive or react with side effects to gold salts or Dpenicillamine, or both. At a dosage of $1 \cdot 5-2 \cdot 5$ $\mathrm{mg} / \mathrm{kg} / \mathrm{day}$ the toxic reactions of azathioprine are moderate and limited mainly to gastrointestinal and mild haematological complications. ${ }^{1}$ ?

Pancytopenia in relation to this drug is a rare side effect. So far, 18 cases of pancytopenia during azathioprine treatment used for a variety of diseases, given in different dosages and in combination with different other drugs, have been reported world wide. ${ }^{3}$ Detailed descriptions of these cases are mostly lacking.

We report two patients with rheumatoid arthritis who developed pancytopenia while receiving azathioprine $100 \mathrm{mg}$ daily. In one patient platelet transfusion was necessary because of severe thrombocytopenia. The pancytopenia disappeared in both patients after azathioprine treatment was stopped.

\section{Case reports}

CASE 1

A 36 year old woman was diagnosed as suffering from seropositive RA in November 1974. Besides non-steroidal anti-inflammatory drugs she was treated successively with hydroxychloroquine, gold thioglucose, and D-penicillamine. D-Penicillamine

Accepted for publication 20 November 1987

Correspondence to Dr M E C Jeurissen. Department of Rheumatology. University Hospital Nijmegen. Geert Grooteplein Zuid 8 . 6525 GA Nijmegen. The Netherlands. had to be discontinued twice owing to dermatitis. In August 1985 this drug had to be stopped permanently on account of leucopenia $\left(2 \cdot 4 \times 10^{\prime \prime} / 1\right)$ and thrombocytopenia $\left(60 \times 10^{\prime \prime} / 1\right)$. Other abnormal laboratory findings were a positive antinuclear antibody (ANA) test and on immunoblotting weak anti-Sm and antihistone antibodies. Physical examination was normal and there were no signs of active arthritis. Drug induced systemic lupus erythematosus was suspected, and she was treated with prednisone for several months.

Because of active erosive RA involving wrists, knees, and proximal interphalangeal joints of the hands treatment with azathioprine $100 \mathrm{mg}$ daily was started on 12 February 1987. Except for indomethacin $150 \mathrm{mg}$ daily she took no other drug. Three weeks after starting azathioprine RA activity was diminished. Blood tests showed leucopenia of $1.6 \times 10^{9} / 1$ and thrombocytopenia of $78 \times 10^{9} / 1$. Azathioprine was immediately stopped. Five days later the platelet count fell to $27 \times 10^{9} / 1$. Petechiae developed on her legs and she was admitted to hospital. Examination showed little RA activity. Laboratory findings were erythrocyte sedimentation rate (ESR) $60 \mathrm{~mm} / 1 \mathrm{st} \mathrm{h}$, haemoglobin $90.2 \mathrm{~g} / \mathrm{l}$, platelets $18 \times 10^{9} / 1$, leucocytes $1.8 \times 10^{9} / 1$ with $47 \%$ granulocytes. Mean corpuscular volume (MCV) was $81 \mathrm{fmol} / \mathrm{l}$, reticulocytes $0 \cdot 2 \%$. Except for a positive ANA test and anti-double-stranded DNA (antidsDNA) of $57 \mathrm{U} / \mathrm{l}$ (normal less than $20 \mathrm{U} / \mathrm{l}$ ), other laboratory tests, including lactic dehydrogenase, direct Coombs', antibodies to platelets and granulocytes, complement, and immunoblotting, showed no abnormalities. 
HLA analysis was A2 A28 B15 Bw4 Bw6, DR1. DQw1. A bone marrow biopsy showed a hypocellular marrow with a shift of the myeloid series towards immaturity. Megakaryocytes were absent and the erythroid precursors were partly megaloblastic.

The pancytopenia was considered most probably to be related to azathioprine. From the first day in hospital indomethacin was also stopped. Treatment with prednisone $60 \mathrm{mg}$ daily was started and reduced in 10 days to a $5 \mathrm{mg}$ maintenance dose. Two days after admission platelet transfusion was necessary because of a rapid fall of the platelets to $4 \times 10^{y} / 1$. Otherwise there were no other problems. The lowest value of the leucocytes was $1.4 \times 10^{9} / 1$ and of haemoglobin $75.7 \mathrm{~g} / \mathrm{l}$ (Fig. 1).

After three weeks in hospital the patient was dismissed with a haemoglobin of $90 \cdot 2 \mathrm{~g} / \mathrm{l}$, reticulocytes $4.5 \%$, leucocytes $2 \cdot 7 \times 10^{9} / \mathrm{l}$, and platelets $173 \times 10^{9} /$ l. Later a marrow biopsy specimen was completely normal and anti-dsDNA was repeatedly

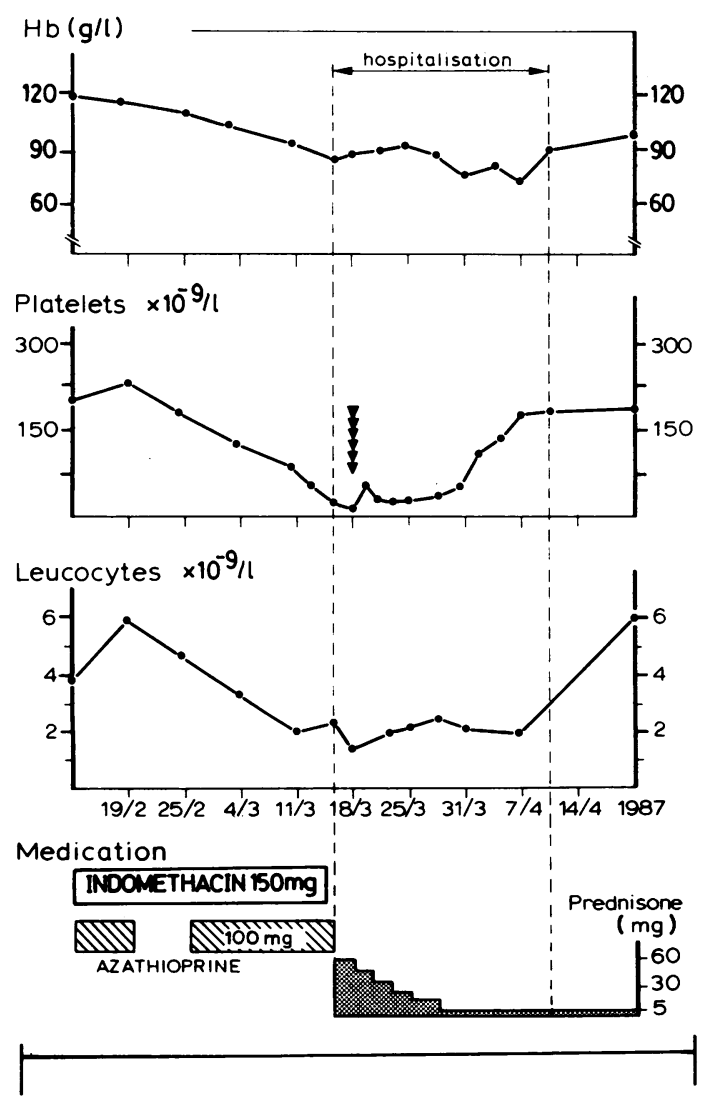

Fig. 1 Haematological changes during azathioprine and indomethacin treatment in patient $1 .(\mathbf{\nabla}=$ one unit of platelet transfusion.) negative. At this time she felt well. Her only treatment being prednisone $5 \mathrm{mg}$ daily.

CASE 2

A 68 year old man was diagnosed as suffering from $\frac{\bar{O}}{\bar{D}}$ seropositive RA in January 1976. He was then $\mathbb{\Phi}$ treated successively with hydroxychloroquine and gold thioglucose. Because of a recurrent duodenal ${ }^{\infty}$ ulcer he received a maintenance dosage of cimeti- $\vec{\circ}$ dine $400 \mathrm{mg}$ daily. In January 1985 hyperuricaemia $\vec{\overrightarrow{ }}$ and nephrolithiasis from urate calculi were detected. $\mathscr{\omega}$ and treatment with allopurinol $100 \mathrm{mg}$ daily was started. One year later he was admitted to hospital? because of active RA involving wrists, knees. proximal interphalangeal and metacarpophalangeal os joints of the hand. Subcutaneous nodules were present. Abnormal laboratory findings were ESR 810 $\mathrm{mm} / \mathrm{lst} \mathrm{h}$, haemoglobin $114.3 \mathrm{~g} / \mathrm{l}$, creatinine $118^{\circ}$ $\mu \mathrm{mol} / \mathrm{l}$, and a creatinine clearance of $70 \mathrm{ml} / \mathrm{min} . \bar{c}$ Treatment with azathioprine $100 \mathrm{mg}$ daily was started. In addition to allopurinol and cimetidine. the patient had taken indomethacin $125 \mathrm{mg}$ daily for $\infty$ several years. At the end of February 1986 a. declining haemoglobin $(82 \cdot 1 \mathrm{~g} / \mathrm{l})$ occurred without melena or positive benzidine reaction. Values of leucocytes and platelets were normal. Gastroscopyo⿳亠二口犬 showed superficial erosions in the bulbus. Two weeks later the patient was readmitted with pancy- $\frac{\mathbb{Q}}{2}$ topenia. Physical examination was unchanged. $\vec{\overrightarrow{ }}$ Laboratory results were as follows: ESR $122 \mathrm{~mm} / 1 \mathrm{st} 3$ h, haemoglobin $69.2 \mathrm{~g} / \mathrm{l}, \mathrm{MCV} 90 \mathrm{fmol} / \mathrm{l}$, reticulo-כ cytes $0 \cdot 1 \%$, platelets $50 \times 10^{9} / \mathrm{l}$, leucocytes $2 \cdot 8 \times 10^{9} / \mathrm{lo}$ with normal differential cell count. Renal function was unchanged. Other laboratory values were nor-⿳⺈, mal, including iron, folic acid, and vitamin $\mathrm{B}_{12} \cdot \frac{\mathrm{\sigma}}{3}$ Bone marrow biopsy showed only a decreased. number of megakaryocytes. After discontinuationo of azathioprine, allopurinol, and indomethacin the counts of leucocytes and platelets returned to응 normal in two weeks. Two units of packed red blood cells were administered. Because of active RA azathioprine was restarted three weeks after adN mission at a dosage of $50 \mathrm{mg}$ but now without allopurinol. Daily blood tests were performed. Theo dosage was increased after one week to $100 \mathrm{mg}$, butw the drug had to be discontinued owing to isolate thrombocytopenia of $107 \times 10^{9} / \mathrm{l}$. As the RA activityo persisted, prednisone $10 \mathrm{mg}$ daily was started ando the platelet count became normal within one week?

\section{Discussion}

These two patients with RA developed pancy $\stackrel{\mathbb{Q}}{\not}$ topenia induced by azathioprine. Bacon et al have reported two patients with this serious side effect. They emphasised in one patient the possible addio 
tional role of allopurinol. In our second patient also allopurinol probably played a part in the development of pancytopenia.

Azathioprine is an imidazole derivative of 6mercaptopurine with immunosuppressive and antiinflammatory effects. Its mode of action is based on incorporation of a false purine, leading to alteration and inhibition of the purine, DNA, and RNA synthesis. Haematological side effects of azathioprine are dependent on the dosage. When the usual dosage $(1.5-2.5 \mathrm{mg} / \mathrm{kg} / \mathrm{day})$ is given the interval before maximum bone marrow suppression is about two weeks. ${ }^{5}$ We found the same interval in patient 1 .

Leucopenia is the most frequent haematological complication of azathioprine treatment. In published reviews about this adverse drug reaction in patients with RA the incidence of leucopenia ranges from 11 to $14 \cdot 5 \% .^{12}$ Agranulocytosis within one week of azathioprine administration is very rare and possibly an idiosyncratic reaction. ${ }^{5}$ Other haematological changes are thrombocytopenia, anaemia, and macrocytosis. Thrombocytopenia is an uncommon side effect reported in $0.8-4.8 \%$ of cases. ${ }^{12}$ It rarely develops without leucopenia. In our second patient isolated thrombocytopenia developed two weeks after restarting azathioprine. Pure red cell aplasia induced by azathioprine is a very rare adverse reaction. It reflects a selective toxic effect of azathioprine on erythropoiesis. ${ }^{67}$ Macrocytosis has been reported in transplant recipients and ascribed to interference with DNA synthesis. ${ }^{7-9}$ It is unrelated to the metabolism of folic acid or vitamin $B_{12}$, or both. In our patients we could not find a significant alteration in the MCV. In the second patient a declining haemoglobin concentration occurred two weeks before the leucopenia and thrombocytopenia. When the negative result of the gastroscopy and the laboratory values are considered the anaemia appears to be related to azathioprine.

In the case of patient 1 the general practitioner had not brought to our notice the haematological changes (leucocytes $3.3 \times 10^{9} / l$, platelets $123 \times 10^{9} / l$ ) a week before she visited us. At that time we could have discontinued or diminished the dosage. An additional toxic effect of indomethacin on the bone marrow was unlikely because she had taken that drug for many years. In retrospect, owing to the absence of megakaryocytes from the bone marrow and the absence of antibodies to granulocytes and platelets, the indications for administering high dosage prednisone were debatable. As she had developed leucopenia and thrombocytopenia while taking D-penicillamine in the past she may have been predisposed to bone marrow suppression due to different drugs.
There are several reports of pancytopenia due to the combination of azathioprine and allopurinol, ${ }^{1(1-12}$ as occurred in patient 2. Azathioprine is rapidly converted to 6-mercaptopurine. The major metabolite of 6-mercaptopurine, 6-thiouric acid, is excreted in the urine. The enzyme xanthine oxidase is responsible for this oxidation. Allopurinol inhibits this enzyme and so administration of azathioprine together with allopurinol gives rise to an increased 6-mercaptopurine blood concentration, which can induce bone marrow toxicity. If it is necessary to administer both drugs it is advisable to reduce the usual dose of azathioprine by about $75 \% .^{35}$ In patient 2 this rule was unfortunately not applied.

Finally, when azathioprine is prescribed, close clinical and laboratory controls are necessary. Increased toxicity due to additional drugs has to be considered. Fortunately, both these patients recovered completely from this rare but dangerous adverse reaction to azathioprine.

We wish to thank Mrs Marion Janssen for her excellent secretarial help.

\section{References}

1 Whisnant J K. Pelkey J. Rheumatoid arthritis: treatment with azathioprine (Imuran( $R)$ ). Clinical side-effects and laboratory abnormalitics. Ann Rheum Dis 1982: 41 (suppl): 44-7.

2 Bunch Th W. O'Duffy D M. Discase modifying drugs for progressive rheumatoid arthritis. Series on pharmacology in practice. Mayo Clin Proc 1980: 55: 161-79.

3 Lawson D H. Lovatt G E. Gurton G S. Hennings R C. Adverse effects of azathioprinc. Adverse Drug React Acute Poisoning Rev 1984: 3: 161-71.

4 Bacon B R. Treuhaf W H. Goodman A M. Azathioprineinduced pancytopenia. Arch Intern Med 1981: 141: 223-6.

5 Decker J L. Steenberg A D. Immunoregulatory drugs. In: McCarty D J. cd. Arthritis and allied conditions. Philadelphia: Lec and Febiger. 1985: 529-30.

6 Old C W. Flannery E P. Grogan Th M. Stone W H. San Antonio R P. Azathioprine induced pure red blood cell aplasia. JAMA 1978: 240: 552-4.

7 Mcgrath B P. Ibcls L S. Raik E. Erythroid toxicity of azathioprinc. $Q J$ Med 1975: 173: 57-63.

8 Nicholls A J. Davidson R J L. Development of macrocytosis during azathioprine therapy after renal transplantation. Transplantation 1978: 27: 220-1.

9 Wickramasinghe S N, Dodsworth H, Rault R M J. Observations on the incidence and cause of macrocytosis in patients on azathioprine following renal transplantation. Transplantation 1974: 18: 443-6.

10 Reinicke H. Weber F W. Hausamen T U. Myelosuppression mit Makrozytärer Anämic und Leukopenic unter Behandlung mit Azathioprine bei Myastenia gravis. Dtsch Med Wochenschr 1982: 107: 1592-4.

11 Zazgornik J. Kopsa H. Schmidt P. Pils P. Kuschan K. Deutsch $E$. Increased danger of bone marrow damage in simultaneous azathioprine-allopurinol therapy. Int J Clin Pharmacol Ther Toxicol 1981; 19: 96-7.

12 Glogner P. Henri N. Panzytopenic nach Kombinationsbehandlung mit Allopurinol und Azathioprine. Medizinische Welt 1976: 277: 1545-6. 